\title{
Article
}

\section{The Comparison of Clinical Result between Primary Repair of the Anterior Cruciate Ligament with Additional Internal Bracing and Anatomic Single Bundle Reconstruction-A Retrospective Study}

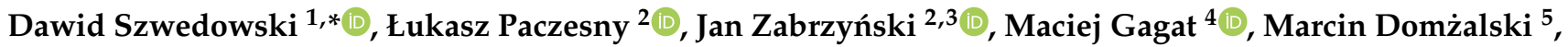 \\ Gazi Huri ${ }^{6}$ and Wojciech Widuchowski ${ }^{7}$
}

check for updates

Citation: Szwedowski, D.; Paczesny, Ł.; Zabrzyński, J.; Gagat, M.;

Domżalski, M.; Huri, G.;

Widuchowski, W. The Comparison of Clinical Result between Primary Repair of the Anterior Cruciate Ligament with Additional Internal Bracing and Anatomic Single Bundle Reconstruction-A Retrospective Study. J. Clin. Med. 2021, 10, 3948. https://doi.org/10.3390/ jcm10173948

Academic Editors: Yong Seuk Lee and Emmanuel Andrès

Received: 18 June 2021

Accepted: 23 August 2021

Published: 31 August 2021

Publisher's Note: MDPI stays neutral with regard to jurisdictional claims in published maps and institutional affiliations.

Copyright: (C) 2021 by the authors. Licensee MDPI, Basel, Switzerland. This article is an open access article distributed under the terms and conditions of the Creative Commons Attribution (CC BY) license (https:/ / creativecommons.org/licenses/by/ $4.0 /)$.
1 Orthopaedic Arthroscopic Surgery International (OASI) Bioresearch Foundation, 20133 Milan, Italy

2 Citomed Healthcare Center, Department of Orthopaedics, Orvit Clinic, Sklodowskiej 73, 87-100 Toruń, Poland; drpaczesny@gmail.com (Ł.P.); zabrzynski@gmail.com (J.Z.)

3 Department of General Orthopedics, Musculoskeletal Oncology and Trauma Surgery, University of Medical Sciences, 61-701 Poznan, Poland

4 Department of Histology and Embryology, Faculty of Medicine, Collegium Medicum in Bydgoszcz, Nicolaus Copernicus University in Torun, 85-067 Bydgoszcz, Poland; mgagat@cm.umk.pl

5 Department of Orthopedic and Traumatology, Veterans Memorial Hospital, Medical University of Lodz, 90-549 Lodz, Poland; marcindomzalski@yahoo.com

6 Orthopaedics and Traumatology Department, Hacettepe Universitesi, Ankara 06100, Turkey; gazihuri@yahoo.com

7 Department of the Knee Surgery, Arthroscopy and Sports Traumatology, District Hospital of Orthopedics and Trauma Surgery, 41-940 Piekary Slaskie, Poland; sportmed@sportmed.com.pl

* Correspondence: dszwedow@yahoo.com

Abstract: Background: The current standard of treatment of anterior cruciate ligament (ACL) is reconstruction (ACLR). This technique has some disadvantages: poor proprioception, donor site morbidity and the inability to restore joint kinematics. ACL repair could be an alternative treatment. The purpose of the study was to compare the stability and the function after ACL primary repair versus single-bundle ACLR. Methods: In a retrospective study, 12 patients underwent primary ACL repair with internal bracing, 15 patients underwent standard ACLR. Follow-up examinations were evaluated at up to 2 years postoperatively. One patient in the ACL repair group was lost to followup due to re-rupture. The absolute value of anterior tibial translation (ATT) and the side-to-side difference in the same patient $(\triangle \mathrm{ATT})$ were evaluated using the GNRB arthrometer. The Lysholm knee scoring was obtained. Re-ruptures and other complications were recorded. Results: Anterior tibial translation (ATT) was significantly decreased in the ACL repair group compared with the ACLR group (5.31 mm vs. $7.18 \mathrm{~mm}$, respectively; $p=0.0137$ ). Arthrometric measurements demonstrated a mean side-to-side difference $(\triangle \mathrm{ATT}) 1.87$ (range 0.2 to 4.9 ) $\mathrm{mm}$ significantly decreased compared to ACLR 3.36 (range 1.2-5.6 mm; $p=0.0107$ ). The mean Lysholm score was 85.3 points in the ACL repair group and 89.9 in ACLR group. No significant differences between ACL repair and ACLR were found for the Lysholm score. There was no association between AP laxity and clinical outcomes. There were two complications in the internal bracing group: one patient had re-rupture and was treated by ACLR, another had limited extension and had arthroscopic debridement. Conclusions: Anterior tibial translation was significantly decreased after ACL repair. Additionally, the functional results after ACL repair with internal bracing were comparable with those after ACLR. It should be noted that the two complications occurred. The current study supports further development of ACL repair techniques.

Keywords: anterior cruciate ligament (ACL); primary ACL repair; internal bracing; knee laxity 


\section{Introduction}

Responsible for controlling anterior-posterior (AP) and rotatory knee laxity, the anterior cruciate ligament (ACL) is the major knee joint stabilizer. The growing popularity of recreational and competitive sport activities has contributed to an increased number of ACL injuries in the past three decades. Due to the limited healing potential of the ligament, ACL reconstruction (ACLR) is the gold standard in ACL injury treatment [1]. The administration of platelet-rich plasma (PRP), which comprises growth factors and displays evident biological activity [2,3], showed promise in stimulating ACL healing. However, PRP augmentation has failed to provide superior functional results in combination with ACLR [4,5]. Thus, improved patient selection and the latest advances in arthroscopic techniques, such as internal bracing, have aroused renewed interest in ACL repair [6-9]. These methods offer potential advantages, including native ACL preservation, reduced proprioception loss and no autologous graft harvesting-associated morbidity.

Furthermore, some authors contend that there may be a lower risk of posttraumatic osteoarthritis after repair [10,11]. The rationale for internal bracing augmentation is to diminish the gap between the injured sites and protect ACL healing during early mobilization and rehabilitation $[7,12,13]$. Additionally, it has been demonstrated in preclinical studies that providing repaired tissue with some mechanical support resulted in the enhancement of the biomechanical properties of the ACL [14-16]. Despite the fact that researchers have not reported any exact threshold for anterior knee laxity that would allow for scar tissue attachment back to the bone, increased anteroposterior translation can result in compromised healing capability and an inability to form stable scar tissue [17-19]. The purpose of this study was to evaluate the clinical results after ACL repair compared to single-bundle ACLR. It was hypothesized that arthroscopic ACL repair with additional internal bracing would result in good knee stability and subjective outcomes comparable to ACL reconstruction. Considering that one of the major problems during ACL repair is insufficient postoperative knee stability, we decided to focus on this particular issue.

\section{Materials and Methods}

We retrospectively followed a group of 12 patients who underwent primary ligament repair with internal bracing augmentation and 15 patients who underwent single-bundle ACL reconstruction to have complete ACL tears treated at our institution between 2017 and 2019 (Figure 1).

The inclusion criteria consisted of an acute, complete ACL injury, diagnosed within 6 weeks of injury, in patients with symptomatic instability. The exclusion criteria consisted of ACL tears in which the ligamentous fibers could not be reapproximated with suturebracing, $\leq \mathrm{G} 1$ pivot-shift instability, significant malalignment, chondral defect or meniscal injury, multiligament injury, contralateral knee injury. All patients with ACL ruptures were assessed with MRI. The possibility of internal bracing repair was discussed with the patient in the event that femoral side tear was found. If the patient revealed interest in this kind of treatment, the final decision was made depending on the exact quality and mobility of the stump.

Despite a lack of patient randomization, parameters such as age, sex and time since injury were similar in both the study group, which underwent ACL repair and the control group, which underwent ACLR.

The senior author (Ł.P.) performed all procedures conducted within 8 weeks of the injury. Non-operative and operative treatment protocols were discussed with each patient prior to treatment. Standard ACL reconstruction methods were specifically discussed as an alternative to primary repair with internal bracing. Patients who did not consent to the ACL repair method underwent standard ACL reconstruction with hamstring autografts. The Lysholm Knee Questionnaire was used to conduct a retrospective follow-up of all patients. Anterior knee laxity was evaluated postoperatively by an independent examiner who measured the side-to-side difference in anterior tibial translation in millimeters with a GNRB arthrometer (Genourob, Laval, France). Throughout the follow-up, postoperative 
complications, recurrent instability and reinjury were documented. The study protocol was approved by the local institutional ethics committee.

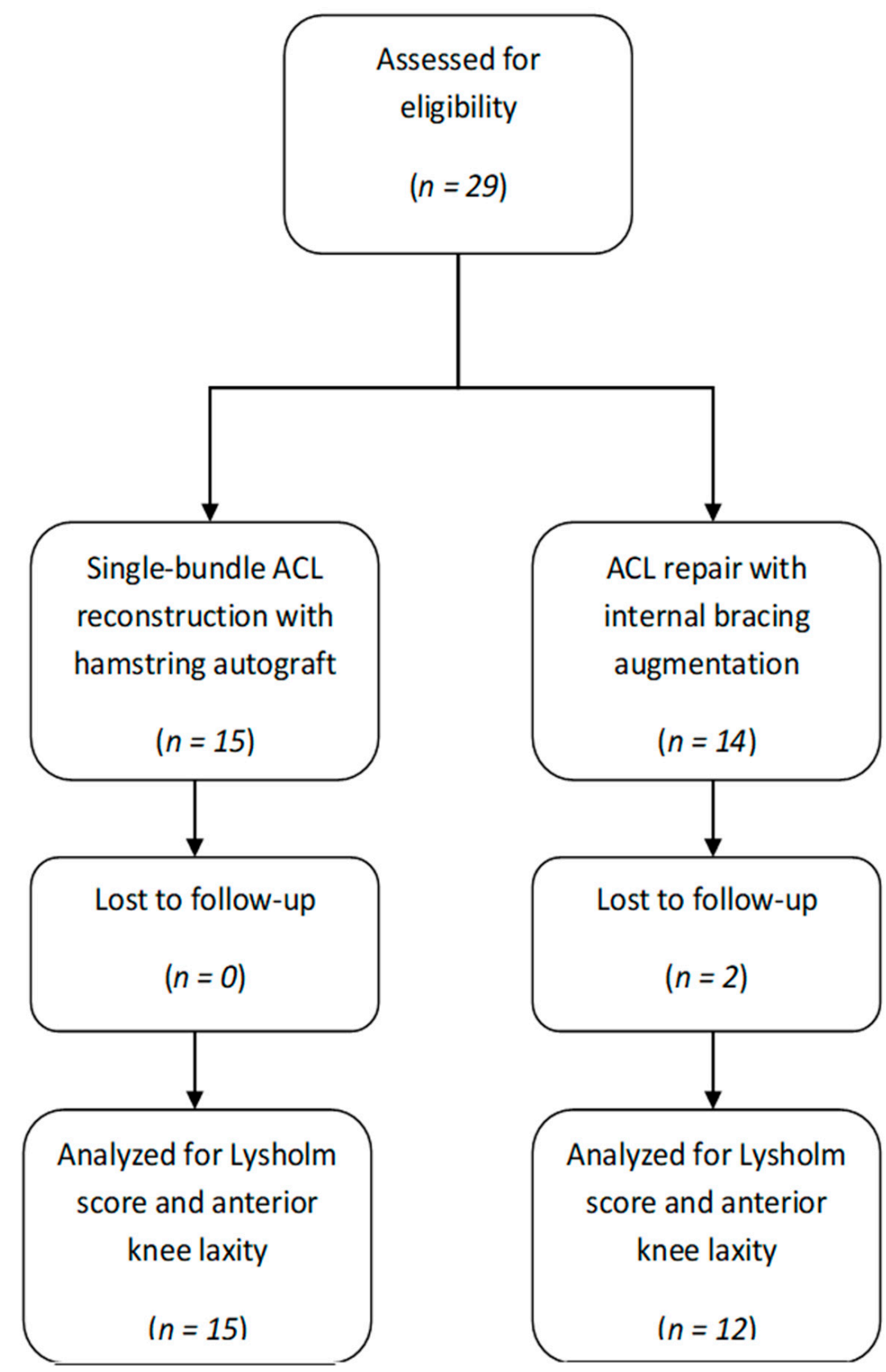

Figure 1. The flowchart presenting the study design.

\subsection{Surgical Technique}

Patients were positioned supine, as is typical of knee arthroscopy and standard ACL reconstruction and were administered a spinal or general anesthetic. Under anesthesia, the patient's knee was examined to establish whether its instability corresponded with ACL insufficiency. Diagnostic arthroscopy was performed to examine the ACL and to confirm a complete tear amenable to the primary repair technique. The Lachman test was performed under direct visualization. Patients with a complete ACL tear that had sufficient distal remnant length and tissue quality to reapproximate the remnants underwent ACL repair. ACL repair with the internal bracing technique has been described in previously published technical notes [20]. Primary ligament repair is depicted in Figure 2. 


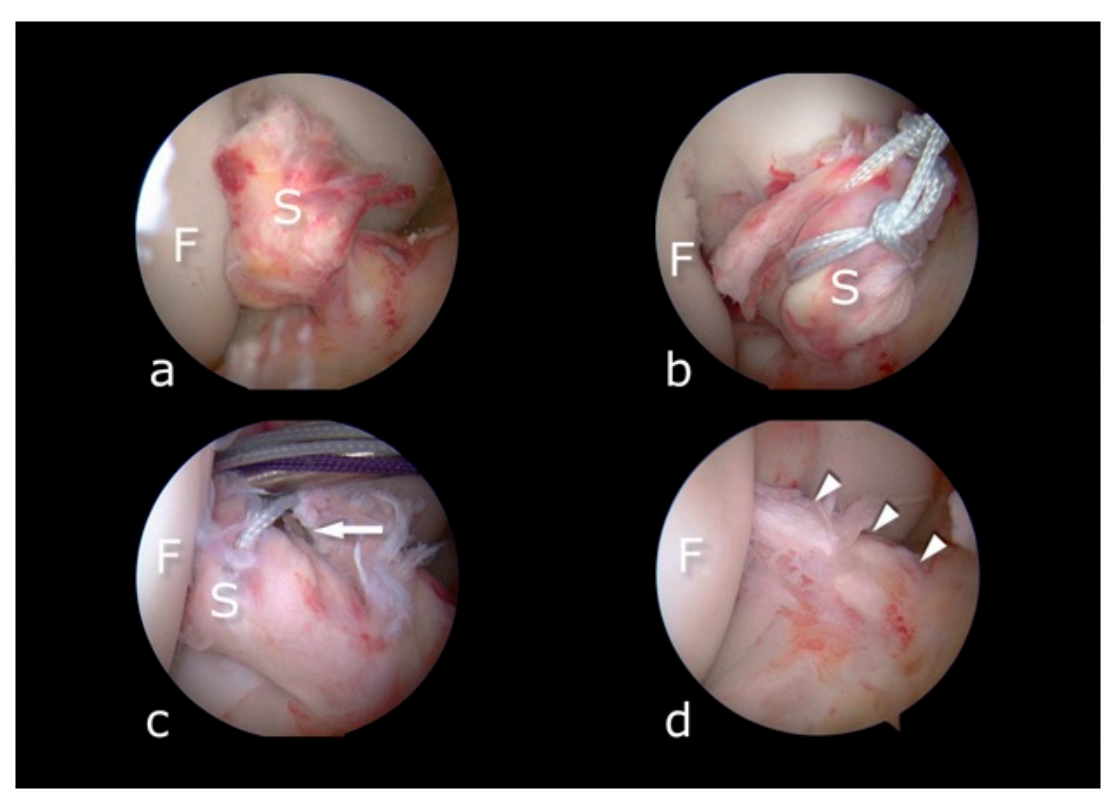

Figure 2. (a) Fresh ACL rupture. Stump (S) is waving in front of the intercondylar notch of the femur (F). (b) The stump (S) is sutured by means of the closed-loop FiberLink sutures and retracted from the femoral bone (F). (c) After preparation of the femoral tunnel the stump (S) is repositioned to meet native insertion on the femur (F). Next, the tibial tunnel is drilled. The drill tip is visible in the center of the stump (arrow). (d) After completion of the procedure, the tension of the repaired ACL (arrowheads) and FiberTape is checked and a full range of motion confirmed.

The standard ACL reconstruction technique was performed in line with Siebold's guidelines [21] in the same patient setting after arthroscopic evaluation of the joint. After complete ACL injury was confirmed, a $3 \mathrm{~cm}$ oblique incision over the hamstring insertion was made and the semitendinosus plus gracilis tendons were harvested. The graft was double folded, prepared and measured and the femoral tunnel was drilled in compliance with the anteromedial technique aiming at femoral insertion of the native ACL. Next, the tibial tunnel was drilled with the use of an elbow guide. The graft was passed through and anchored on the femoral cortex using the Endobutton system (Smith and Nephew, USA). Distal fixation was achieved with a titanium RCI screw whose diameter corresponded with that of the graft.

\subsection{Rehabilitation Protocol}

Although external braces were not used in the internal bracing group, the ACL reconstruction group was provided with external hinge braces for 6 weeks without limiting the range of motion (ROM) (Protect 4 Evo, Medi, Bayreuth, Germany). The same rehabilitation protocol described by Królikowska et al. [22-24] was used in both groups. Partial weight-bearing with the assistance of crutches was allowed as tolerated. Progression to weight-bearing was permitted after 3 weeks, while the full active range of motion was allowed 6 weeks after the surgery.

\subsection{Anterior Knee Laxity Measurement}

Several arthrometers are widely used to measure knee joint sagittal stability; the KT1000 (MED metric, San Diego, CA, USA) and the Rolimeter (Aircast, Summit, NJ, USA) are the most popular devices at present because of their simplicity of use. The KT-1000 and the Rolimeter [25,26] are equally reliable and operator-dependent [27-30]. Considerably more reproducible than the other tools, regardless of the tester's experience [31,32], the GNRB arthrometer was used to objectively assess anterior tibial translation. As an additional benefit, the measurement was achieved independent of the uninvolved side [32]. 
Reproducing the Lachman test position (Figure 3), the GNRB is a knee laxity testing device that measures AP tibial translation at $20^{\circ}$ of knee flexion.

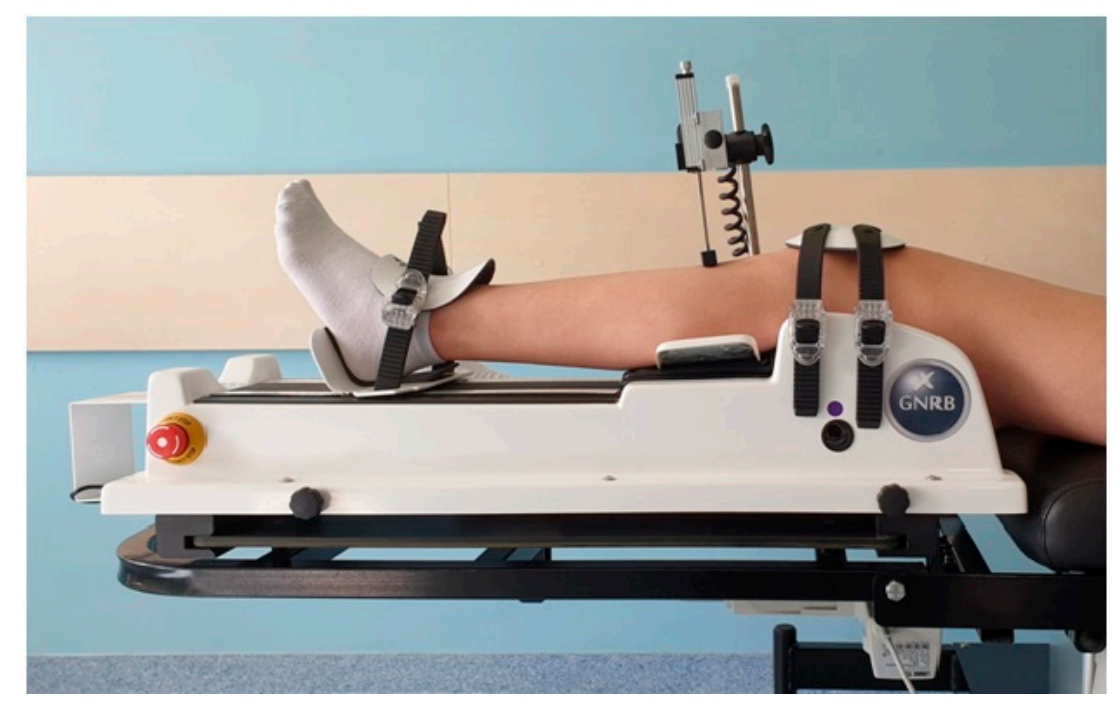

Figure 3. The patient was lying on a standard examination table in the supine position with the arms placed along the body, each knee being comparatively tested, the healthy knees are investigated first. The lower limb is placed in rigid adjustable leg support, with the knee placed at $0^{\circ}$ of rotation. The knee should be placed so that the inferior pole of the patella corresponds to the lower border of the patellar support, the joint line is palpated and should be located between the support and the jack.

The AP laxity measurement was performed using a protocol previously described by Nouveau et al. [33].

\subsection{Statistical Analysis}

Data analysis was performed with MedCalc Statistical Software (version 16.4.3; MedCalc Software, Ostend, Belgium), while Shapiro-Wilk tests were used to assess the normality of continuous variables. The correlation of variables within patients was established with the Spearman Rho correlation coefficient and the Mann-Whitney U test served to enable the statistical comparison of independent data. All comparisons between groups and the statistical analysis were blinded and performed by an independent investigator. A $p$-value $<0.05$ was considered statistically significant. The sample size for our study was based on the results of a previous study on ACL primary repair [33]. A sample size calculation showed that 12 patients per group would be required to detect a difference in anterior knee laxity with a standard deviation of two points with a power of $80 \%$ and a significance level of $\alpha=0.05$.

\section{Results}

In the examined cohort, 12 patients underwent internal bracing repair of the ACL, while 15 patients underwent ACL reconstruction. One patient in the ACL repair group was lost to follow-up due to re-rupture. The mean age in the ACL repair group was 36 (range: 15-55) years. This study group included six males and five females (seven right knees and four left knees). All of the patients suffered from an acute knee injury 1-2 months preoperatively. The average time from surgery to follow-up in the ACL repair with additional internal bracing group was 14.8 (range 5-24) months and for patients treated with ACLR, 13.6 (range 10-24) months. There were no statistically significant differences of the demographic data between two groups. Anterior tibial translation (ATT) was significantly decreased in the ACL repair group compared with the ACLR group (5.31 $\mathrm{mm}$ vs. $7.18 \mathrm{~mm} ; p=0.0137$ ) (Figure 4). 


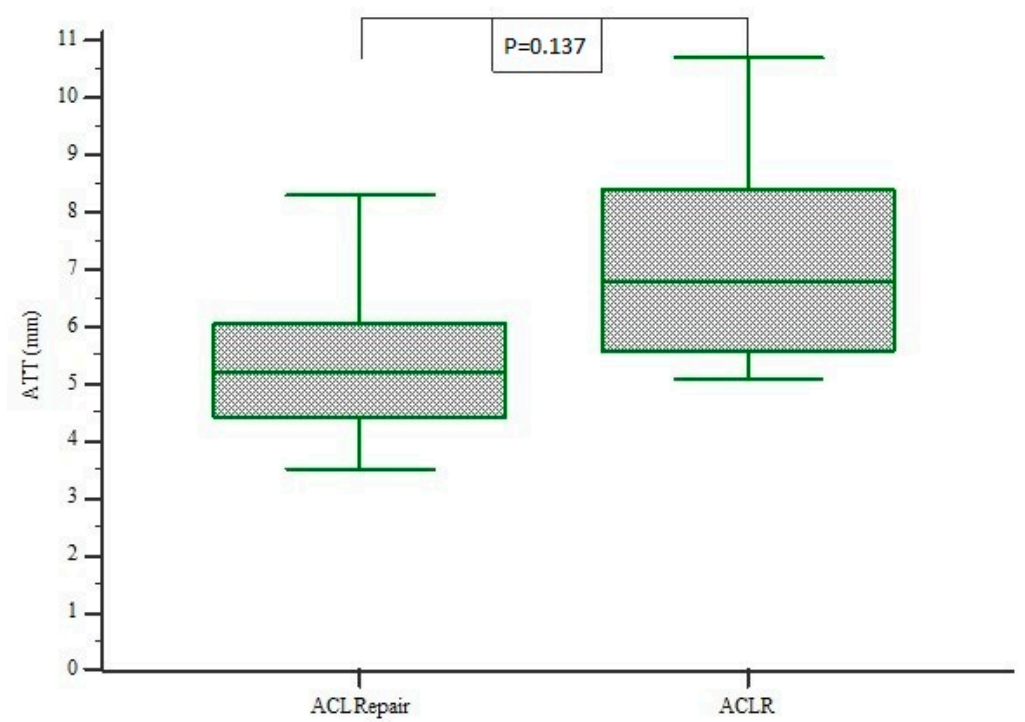

Figure 4. Box plot of assessments of anterior tibial translation (ATT) comparing the difference between ACL repair and ACLR group. ATT was significantly decreased in the ACL repair group compared with the ACLR group (5.31 mm vs. $7.18 \mathrm{~mm}$, respectively; $p=0.0137$ ).

Moreover, GNRB measurements demonstrated a significantly decreased mean sideto-side difference ( $\triangle \mathrm{ATT}$ ) at 1.87 (range 0.2 to 4.9$) \mathrm{mm}$ when compared to ACLR at 3.36 (range 1.2 to $5.6 \mathrm{~mm} ; p=0.0107$ ) (Figure 5).

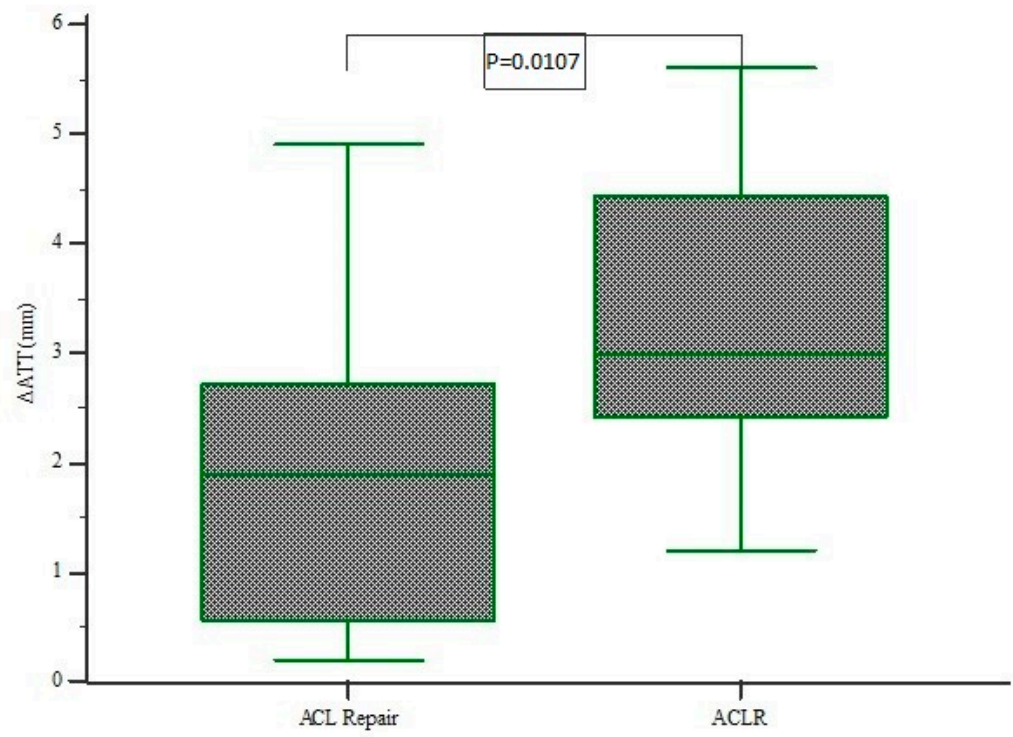

Figure 5. Box plot of assessments of side-to-side difference ( $\triangle \mathrm{ATT})$ in ACL repair and ACLR group. It demonstrates a mean side-to-side difference 1.87 (range 0.2 to 4.9 ) $\mathrm{mm}$ in ACL repair significantly decreased compared to ACLR 3.36 (range 1.2 to $5.6 \mathrm{~mm} ; p=0.0107$ ).

The mean Lysholm score after 12 months was 89.2 (range: 57-100) in the internal bracing cohort and 89.9 (range: 67-100) in the ACLR group. No significant differences between ACL repair and ACLR were found for the Lysholm score $(p=0.9793)$ (Figure 6). Additionally, no correlation was demonstrated between Lysholm scores and ATT for either surgical technique $(p>0.05)$. 


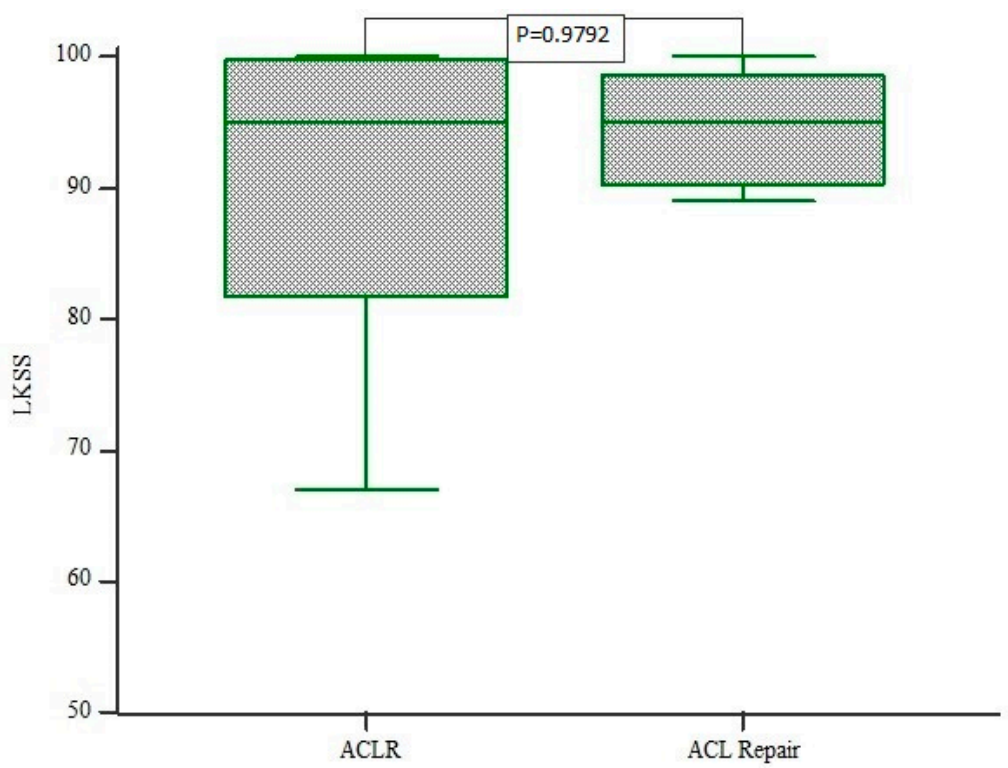

Figure 6. Box plot of Lysholm score assessments comparing ACL repair and ACLR group. The mean Lysholm score after 12 months was 89.2 (range: 57-100) in the internal bracing cohort and 89.9 (range: 67-100) in the ACLR group. There were no statistically significant differences between both groups $(p=0.9793)$.

Two complications occurred in the internal bracing cohort: one patient suffered from re-rupture 8 months after the primary surgery and was treated with ACLR (Figure 7), while the other had limited extension and underwent arthroscopic debridement of scar tissue in the intercondylar notch.

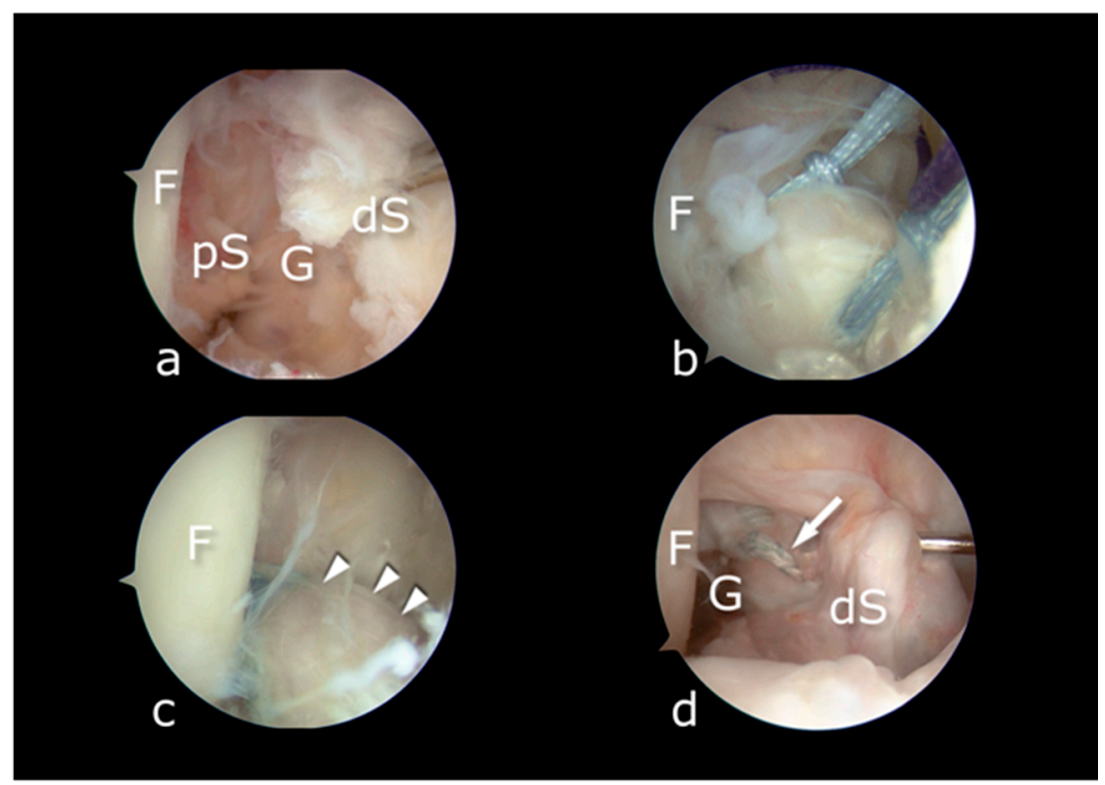

Figure 7. (a) Primary ACL repair. Distal stump (dS) is waving in front of the intercondylar notch of the femur (F). Proximal stump (pS) is visible. (b) The stump is sutured by two closed-loop FiberLink sutures and retracted from the femoral bone (F). (c) After completion of the procedure, the tension of the repaired ACL (arrowheads) and FiberTape is checked. (d) Revision surgery. Re-rupture of the construct is visible with gap $(\mathrm{G})$ opening. Distal stump is folding and hook traction reveals FiberLink sutures (arrow). 
Second-look arthroscopy in the latter case revealed a well-healed ACL (Figure 8). There were no wound infections during the follow-up period.

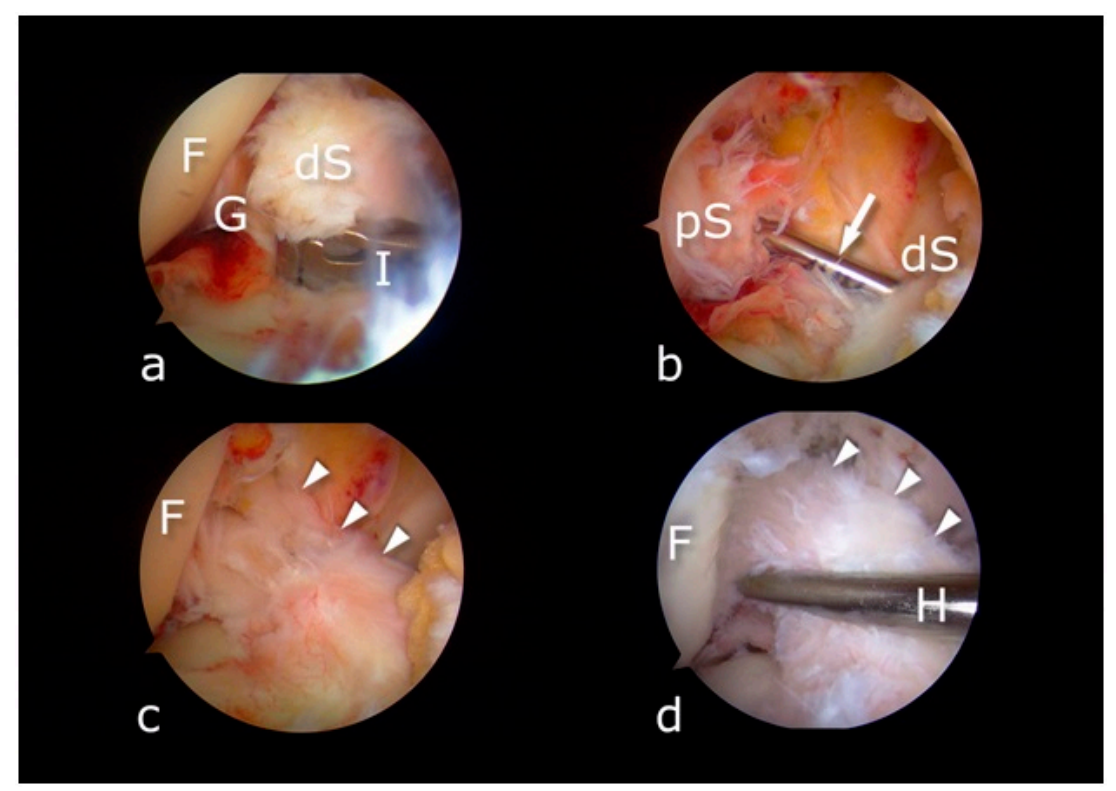

Figure 8. (a) Primary ACL repair. Distal stump (dS) waving in front of the intercondylar notch of the femur $(\mathrm{F})$ with a gap $(\mathrm{G})$ opening after retraction by suturing instrument (I). (b) Proximal stump (pS) drilled (arrow). Distal stump (dS) was retracted at this stage. (c) After completion of the procedure, the tension of the repaired ACL (arrowheads) and FiberTape was confirmed. (d) Second look surgery due to poor range of motion. After scaring tissue removal physiological tension of the healed ACL was confirmed by hook $(\mathrm{H})$ traction.

\section{Discussion}

The most essential finding in the study was that ACL repair with internal bracing resulted in significantly smaller anterior knee laxity than ACLR. In a systemic review, Kandhari et al. emphasized that the parameters of knee laxity were not explicitly reported in previous clinical ACL repair studies [34]. AP laxity is important because it is associated with the extent of tibiofemoral cartilage damage after ACL surgery [35]. Several studies have demonstrated good knee stability measured on the KT-1000 [36-43] and the Rolimeter [44] after primary ACL repair. Although a majority of clinical studies use these tools for anterior tibial translation, it must be kept in mind that these devices are examiner dependent. Collete et al. demonstrated that GNRB revealed superior intra- and inter-examiner reproducibility over KT-1000. Additional advantages of this tool include better control of the magnitude, direction and rate of force application as well as hamstring activity [32]. Other studies demonstrated that ACL tears were diagnosed more accurately with the GNRB than with the Telos stress device (Gmbh, Hungen/Obbornhafen, Germany) [13,31]. However, in a more recent study, no significant differences were found between these two instruments in reproducibility for measuring anterior tibial translation without rotation in normal knees [45]. Comparing the GNRB with the computer navigation system, Jenny et al. validated the device and concluded that the differences between the measurements made with the use of the GNRB and the navigation system were insignificant and unlikely to have any clinical impact [42]. To the best of our knowledge, this is the first study using a GNRB arthrometer to measure anterior tibial translation after ACL repair.

The loss of ACL stability poses a major challenge to ACL repair efficacy. Out of several different techniques proposed, such as sutures [43] and anchors [36-38,42], augmenting the primary repair construct with internal sutures provides additional stability and better healing potential [14-16]. Murray et al. showed that providing additional stabilization between the tibia and the femur contributes to the enhancement of the structural properties 
of ACL repairs when compared with the suture technique [14]. Similarly, Seitz et al. demonstrated superior biomechanical properties, such as stiffness and tensile strength and less AP laxity for ACL repair with polyethylene terephthalate band augmentation [15]. On the basis of a porcine model, Fleming et al. [13] showed that isolated augmentation resulted in knee laxity values that were within $0.5 \mathrm{~mm}$ of the intact ACL joint when the sutures were tied with the knee at $60^{\circ}$ flexion. Laxity values were evaluated after cyclical shear loading in compliance with the Lachman test and primary suture repair without augmentation significantly increased anterior laxity compared with the normal knee. In a recent study, Bachmaier et al. [19] proved the internal brace to be a protective primary stabilizer and provided reduced peak loads on ACL repair as well as gap formation of less than $3 \mathrm{~mm}$ because it possessed a synergistic load-sharing function with ACL repair in a porcine model. By the simulation of loads up to $350 \mathrm{~N}$ experienced during late rehabilitation, they concluded that the internal bracing of ACL repair ensured adequate stabilization to protect the healing ACL at loads affecting an intact knee during usual everyday activity. Another cadaveric study showed that anterior knee laxity after augmented ACL repair was comparable to the range of an intact knee [38].

Furthermore, we did not detect any disparity in clinical outcomes between ACL repair and ACLR. Recent studies have demonstrated that primary repair may lead to good clinical results. For example, Van Heusden et al. reported excellent outcomes of primary repair with additional internal bracing in 42 patients with $4.8 \%$ failures at a 2-year follow-up [13], while Jonkergouw et al. used internal bracing augmentation in some patients $(27 / 56)$ who underwent a suture anchor repair technique for proximal ACL tears. No significant discrepancy in clinical outcome scores or failure rates at a mean follow-up of 38.4 months was demonstrated [8]. Similarly, our study did not show any major difference between ACLR and ACL repair in clinical outcomes.

Both complications that occurred in the ACL repair group, i.e., re-ruptures and a limited range of motion can be connected with the over stiffened construct of the repaired ACL. With high success rates for return-to-play typically reported [45], ACLR is the procedure of choice in ACL insufficiency treatment; nevertheless, manifest disadvantages of this procedure comprise a loss of proprioception, donor site morbidity, incomplete return to high-demand sports and the inability to restore normal kinematics of the knee joint $[42,43]$. In view of the fact that ACL injuries typically occur in a younger demographic, new approaches that can restore the near-anatomic function of this ligament have the potential to become widely used in clinical practice.

Despite several strengths, the major limitations of our study are the small number of patients included, short follow-up duration and retrospective analysis of data. Another limitation is the lack of MRI and 2nd look arthroscopic findings in all cases. Additionally, the fact that the GNRB arthrometer is a robotic device and is thus very sensitive to changes in positioning could lead to low interrater reliability of this tool. It should also be noted that patients were not randomized; therefore, further studies are required.

\section{Conclusions}

The clinical results of ACL repair are similar to those after ACL reconstruction, which was also confirmed by other comparative studies. Although we did not detect any major disparities between ACL repair with internal bracing and anatomic single-bundle reconstruction with respect to objective knee laxity, we noticed some complications in the ACL repair group.

Author Contributions: Conceptualization D.S. and Ł.P.; methodology, D.S. and Ł.P.; software, J.Z.; validation, M.D., W.W. and G.H.; data curation, M.G.; writing-original draft preparation, D.S.; writing—review and editing M.G., Ł.P., M.D., W.W. and G.H.; visualization, Ł.P.; supervision, M.D., M.G. and Ł.P.; project administration, D.S. and Ł.P. All authors have read and agreed to the published version of the manuscript.

Funding: This research received no external funding. 
Institutional Review Board Statement: The study was conducted according to the guidelines of the Declaration of Helsinki and approved by the Institutional Review Board of Collegium Medicum in Bydgoszcz (KB 159/2018).

Informed Consent Statement: Informed consent was obtained from all subjects involved in the study.

Data Availability Statement: The data from this study are available from the corresponding author upon reasonable request.

Conflicts of Interest: The authors declare no conflict of interest.

\section{References}

1. Murray, M.M.; Kalish, L.A.; Fleming, B.C.; Flutie, B.; Freiberger, C.; Henderson, R.N.; Perrone, G.S.; Thurber, L.G.; Proffen, B.L.; Ecklund, K.; et al. Bridge-Enhanced Anterior Cruciate Ligament Repair: Two-Year Results of a First-in-Human Study. Orthop. J. Sports Med. 2019, 7, 2325967118824356. [CrossRef]

2. Bachmaier, S.; DiFelice, G.S.; Sonnery-Cottet, B.; Douoguih, W.A.; Smith, P.A.; Pace, L.J.; Ritter, D.; Wijdicks, C.A. Treatment of Acute Proximal Anterior Cruciate Ligament Tears-Part 1: Gap Formation and Stabilization Potential of Repair Techniques. Orthop. J. Sports Med. 2020, 8, 2325967119897421. [CrossRef]

3. Jonkergouw, A.; Van Der List, J.P.; DiFelice, G.S. Arthroscopic primary repair of proximal anterior cruciate ligament tears: Outcomes of the first 56 consecutive patients and the role of additional internal bracing. Knee Surg. Sports Traumatol. Arthrosc. 2019, 27, 21-28. [CrossRef]

4. Gobbi, A.; Bathan, L.; Boldrini, L. Primary Repair Combined with Bone Marrow Stimulation in Acute Anterior Cruciate Ligament Lesions. Am. J. Sports Med. 2009, 37, 571-578. [CrossRef]

5. Murray, M.M.; Fleming, B.C. Use of a Bioactive Scaffold to Stimulate Anterior Cruciate Ligament Healing Also Minimizes Posttraumatic Osteoarthritis after Surgery. Am. J. Sports Med. 2013, 41, 1762-1770. [CrossRef]

6. Strand, T.; Mølster, A.; Hordvik, M.; Krukhaug, Y. Long-term follow-up after primary repair of the anterior cruciate ligament: Clinical and radiological evaluation 15-23 years postoperatively. Arch. Orthop. Trauma Surg. 2005, 125, 217-221. [CrossRef]

7. van der List, J.P.; DiFelice, G.S. Primary repair of the anterior cruciate ligament: A paradigm shift. Surgeon 2017, 15, 161-168. [CrossRef]

8. Heusdens, C.H.W.; Hopper, G.P.; Dossche, L.; Roelant, E.; Mackay, G.M. Anterior cruciate ligament repair with Independent Suture Tape Reinforcement: A case series with 2-year follow-up. Knee Surg. Sports Traumatol. Arthrosc. 2019, 27, 60-67. [CrossRef]

9. Murray, M.M.; Magarian, E.; Zurakowski, D.; Fleming, B.C. Bone-to-Bone Fixation Enhances Functional Healing of the Porcine Anterior Cruciate Ligament Using a Collagen-Platelet Composite. Arthrosc. J. Arthrosc. Relat. Surg. 2010, 26, S49-S57. [CrossRef]

10. Seitz, H.; Pichl, W.; Matzi, V.; Nau, T. Biomechanical evaluation of augmented and nonaugmented primary repair of the anterior cruciate ligament: An in vivo animal study. Int. Orthop. 2013, 37, 2305-2311. [CrossRef]

11. Seitz, H.; Menth-Chiari, W.A.; Lang, S.; Nau, T. Histological evaluation of the healing potential of the anterior cruciate ligament by means of augmented and non-augmented repair: An in vivo animal study. Knee Surg. Sports Traumatol. Arthrosc. 2008, 16, 1087-1093. [CrossRef] [PubMed]

12. Ahn, J.H.; Chang, M.J.; Lee, Y.S.; Koh, K.H.; Park, Y.S.; Eun, S.S. Non-operative treatment of ACL rupture with mild instability. Arch. Orthop. Trauma Surg. 2010, 130, 1001-1006. [CrossRef] [PubMed]

13. Fleming, B.C.; Carey, J.L.; Spindler, K.P.; Murray, M.M. Can Suture Repair of ACL Transection Restore Normal Anteroposterior Laxity of the Knee? An Ex Vivo Study Braden. J. Orthop. Res. 2008, 26, 1500-1505. [CrossRef] [PubMed]

14. Bachmaier, S.; DiFelice, G.S.; Sonnery-Cottet, B.; Douoguih, W.A.; Smith, P.A.; Pace, L.J.; Ritter, D.; Wijdicks, C.A. Treatment of Acute Proximal Anterior Cruciate Ligament Tears-Part 2: The Role of Internal Bracing on Gap Formation and Stabilization of Repair Techniques. Orthop. J. Sports Med. 2020, 8, 2325967119897423. [CrossRef]

15. van der List, J.P.; DiFelice, G.S. Arthroscopic Primary Anterior Cruciate Ligament Repair with Suture Augmentation. Arthrosc. Tech. 2017, 6, e1529-e1534. [CrossRef]

16. Siebold, R. The concept of complete footprint restoration with guidelines for single- and double-bundle ACL reconstruction. Knee Surg. Sports Traumatol. Arthrosc. 2011, 19, 699-706. [CrossRef]

17. Królikowska, A.; Sikorski, Ł.; Czamara, A.; Reichert, P. Are the knee extensor and flexor muscles isokinetic parameters affected by the duration of postoperative physiotherapy supervision in patients eight months after ACL reconstruction with the use of semitendinosus and gracilis tendons autograft? Acta Bioeng. Biomech. 2018, 20, 89-100. [CrossRef]

18. Królikowska, A.; Sikorski, Ł.; Czamara, A.; Reichert, P. Effects of Postoperative Physiotherapy Supervision Duration on Clinical Outcome, Speed, and Agility in Males 8 Months after Anterior Cruciate Ligament Reconstruction. Med. Sci. Monit. 2018, 24, 6823-6831. [CrossRef]

19. Czamara, A.; Markowska, I.; Królikowska, A.; Szopa, A.; Szopa, M.D. Kinematics of Rotation in Joints of the Lower Limbs and Pelvis during Gait: Early Results-SB ACLR Approach versus DB ACLR Approach. BioMed Res. Int. 2015, 2015, 707168. [CrossRef]

20. Ganko, A.; Engebretsen, L.; Ozer, H. The Rolimeter: A new arthrometer compared with the KT-1000. Knee Surg. Sports Traumatol. Arthrosc. 2000, 8, 36-39. [CrossRef] 
21. Schuster, A.J.; McNicholas, M.J.; Wachtl, S.W.; McGurty, D.W.; Jakob, R.P. A New Mechanical Testing Device for Measuring Anteroposterior Knee Laxity. Am. J. Sports Med. 2004, 32, 1731-1735. [CrossRef]

22. Berry, J.; Kramer, K.; Binkley, J.; Binkley, G.A.; Stratford, P.; Hunter, S.; Brown, K. Error Estimates in Novice and Expert Raters for the KT-1000 Arthrometer. J. Orthop. Sports Phys. Ther. 1999, 29, 49-55. [CrossRef]

23. Muellner, T.; Bugge, W.; Johansen, S.; Holtan, C.; Engebretsen, L. Inter- and intratester comparison of the Rolimeter knee tester: Effect of tester's experience and the examination technique. Knee Surg. Sports Traumatol. Arthrosc. 2001, 9, 302-306. [CrossRef]

24. Papandreou, M.G.; Antonogiannakis, E.; Karabalis, C.; Karliaftis, K. Inter-rater reliability of Rolimeter measurements between anterior cruciate ligament injured and normal contra lateral knees. Knee Surg. Sports Traumatol. Arthrosc. 2005, 13, 592-597. [CrossRef]

25. Huber, F.E.; Irrgang, J.J.; Harner, C.; Lephart, S. Intratester and Intertester Reliability of the KT-1000 Arthrometer in the Assessment of Posterior Laxity of the Knee. Am. J. Sports Med. 1997, 25, 479-485. [CrossRef] [PubMed]

26. Lefevre, N.; Bohu, Y.; Naouri, J.F.; Klouche, S.; Herman, S. Validity of GNRB ${ }^{\circledR}$ arthrometer compared to Telos ${ }^{\mathrm{TM}}$ in the assessment of partial anterior cruciate ligament tears. Knee Surg. Sports Traumatol. Arthrosc. 2014, 22, 285-290. [CrossRef]

27. Collette, M.; Courville, J.; Forton, M.; Gagnière, B. Objective evaluation of anterior knee laxity; comparison of the KT-1000 and GNRB $^{\circledR}$ arthrometers. Knee Surg. Sports Traumatol. Arthrosc. 2012, 20, 2233-2238. [CrossRef] [PubMed]

28. Robert, H.; Nouveau, S.; Gageot, S.; Gagnière, B. A new knee arthrometer, the GNRB ${ }^{\circledR}$ : Experience in ACL complete and partial tears. Orthop. Traumatol. Surg. Res. 2009, 95, 171-176. [CrossRef]

29. Kandhari, V.; Vieira, T.D.; Ouanezar, H.; Praz, C.; Rosenstiel, N.; Pioger, C.; Franck, F.; Saithna, A.; Sonnery-Cottet, B. Clinical Outcomes of Arthroscopic Primary Anterior Cruciate Ligament Repair: A Systematic Review from the Scientific Anterior Cruciate Ligament Network International Study Group. Arthrosc. J. Arthrosc. Relat. Surg. 2020, 36, 594-612. [CrossRef] [PubMed]

30. Kiapour, A.M.; Fleming, B.C.; Murray, M.M. Structural and anatomic restoration of the anterior cruciate ligament is associated with less cartilage damage 1 year after surgery: Healing ligament properties affect cartilage damage. Orthop. J. Sport. Med. 2017, 5, 2325967117723886. [CrossRef] [PubMed]

31. Achtnich, A.; Herbst, E.; Forkel, P.; Metzlaff, S.; Sprenker, F.; Imhoff, A.B.; Petersen, W. Acute Proximal Anterior Cruciate Ligament Tears: Outcomes after Arthroscopic Suture Anchor Repair Versus Anatomic Single-Bundle Reconstruction. Arthrosc. J. Arthrosc. Relat. Surg. 2016, 32, 2562-2569. [CrossRef]

32. Ateschrang, A.; Ahmad, S.S.; Stöckle, U.; Schroeter, S.; Schenk, W.; Ahrend, M.-D. Recovery of ACL function after dynamic intraligamentary stabilization is resultant to restoration of ACL integrity and scar tissue formation. Knee Surg. Sports Traumatol. Arthrosc. 2017, 26, 589-595. [CrossRef]

33. Bigoni, M.; Gaddi, D.; Gorla, M.; Munegato, D.; Pungitore, M.; Piatti, M.; Turati, M. Arthroscopic anterior cruciate ligament repair for proximal anterior cruciate ligament tears in skeletally immature patients: Surgical technique and preliminary results. Knee 2017, 24, 40-48. [CrossRef]

34. Büchler, L.; Regli, D.; Evangelopoulos, D.S.; Bieri, K.; Ahmad, S.S.; Krismer, A.; Muller, T.; Kohl, S. Functional recovery following primary ACL repair with dynamic intraligamentary stabilization. Knee 2016, 23, 549-553. [CrossRef]

35. DiFelice, G.S.; Villegas, C.; Taylor, S. Anterior Cruciate Ligament Preservation: Early Results of a Novel Arthroscopic Technique for Suture Anchor Primary Anterior Cruciate Ligament Repair. Arthrosc. J. Arthrosc. Relat. Surg. 2015, 31, 2162-2171. [CrossRef]

36. Hennings, J. Primary anatomical repair of proximal acl ruptures with suture anchors: 1 year follow-up. Orthop. J. Sports Med. 2018, 6, 2325967118S00023. [CrossRef]

37. Hoffmann, C.; Friederichs, J.; Von Rüden, C.; Schaller, C.; Bühren, V.; Moessmer, C. Primary single suture anchor re-fixation of anterior cruciate ligament proximal avulsion tears leads to good functional mid-term results: A preliminary study in 12 patients. J. Orthop. Surg. Res. 2017, 12, 171. [CrossRef]

38. Kohl, S.; Evangelopoulos, D.S.; Schär, M.; Bieri, K.; Müller, T.; Ahmad, S.S. Dynamic intraligamentarystabilisation. Bone Jt. J. 2016, 98-B, 793-798. [CrossRef]

39. Gobbi, A.; Whyte, G.P. Long-term Outcomes of Primary Repair of the Anterior Cruciate Ligament Combined with Biologic Healing Augmentation to Treat Incomplete Tears. Am. J. Sports Med. 2018, 46, 3368-3377. [CrossRef]

40. Ryu, S.M.; Na, H.D.; Shon, O.J. Diagnostic Tools for Acute Anterior Cruciate Ligament Injury: GNRB, Lachman Test, and Telos. Knee Surg. Relat. Res. 2018, 30, 121-127. [CrossRef]

41. Bouguennec, N.; Odri, G.-A.; Graveleau, N.; Colombet, P. Comparative reproducibility of TELOS ${ }^{\mathrm{TM}}$ and GNRB ${ }^{\circledR}$ for instrumental measurement of anterior tibial translation in normal knees. Orthop. Traumatol. Surg. Res. 2015, 101, 301-305. [CrossRef] [PubMed]

42. Jenny, J.-Y.; Puliero, B.; Schockmel, G.; Harnoist, S.; Clavert, P. Experimental validation of the GNRB ${ }^{\circledR}$ for measuring anterior tibial translation. Orthop. Traumatol. Surg. Res. 2017, 103, 363-366. [CrossRef]

43. Gobbi, A.; Herman, K.; Grabowski, R.; Szwedowski, D. Primary Anterior Cruciate Ligament Repair with Hyaluronic Scaffold and Autogenous Bone Marrow Aspirate Augmentation in Adolescents with Open Physes. Arthrosc. Tech. 2019, 8, e1561-e1568. [CrossRef]

44. DiFelice, G.S.; Van Der List, J.P. Clinical Outcomes of Arthroscopic Primary Repair of Proximal Anterior Cruciate Ligament Tears Are Maintained at Mid-Term Follow-Up. Arthrosc. J. Arthrosc. Relat. Surg. 2018, 34, 1085-1093. [CrossRef] [PubMed]

45. Bonel, H.; Herrmann, G.; Kohlhof, H.; Eggli, S.; Evangelopoulos, D.S.; Ahmad, S.S.; Kohl, S. A novel technique, dynamic intraligamentary stabilization creates optimal conditions for primary ACL healing: A preliminary biomechanical study. Knee 2014, 21, 477-480. 